\title{
No City for Old People
}

\author{
Maria Carreiro E Candido Lopez* \\ Professors of Architecture and researchers UDC, Universidade da Coruña, Spain \\ *Corresponding author: Maria Carreiro E Candido Lopez, Professors of Architecture and researchers UDC, Universidade da Coruña, \\ Spain.
}

To Cite This Article: Maria Carreiro E Candido Lopez. No City for Old People. 2020 - 11(1). AJBSR.MS.ID.001588.

DOI: 10.34297/AJBSR.2020.11.001588.

Received: 海 November 23, 2020; Published: 制 November 30, 2020

\section{Opinion}

Our good friend and neighbor, Miguel R. de la Iglesia, works as a doctor in a primary care center in a traditional and outlying neighborhood of the city of A Coruña (Spain). Among his functions is to visit those patients who cannot travel to his office. Perhaps they are bedridden, very ill; or perhaps convalescent. However, the illness of most is none other than old age and loneliness. They are old, alone and living in aging buildings. They lack the strength to go down and up the stairs that separate them from the street. They have no elevator and no means to install and maintain it. Nor do they have the resources to go to a residence, and quite often they don't want to leave 'their' home either. Without a doubt, the same thing will happen in other areas of our city. The situation of these people is reflected in public statistics. In Spain, one in four households is inhabited by a single person, which means that of all households, $25 \%$ are single-person households. And practically half of these households are inhabited by people over 65 years of age, three out of every four of whom are women. By the way, the Spanish population over that age in 2019 was $19.40 \%$. A situation that marks a trend, or at least marked it until the coronavirus: WHO estimates establish that by 2050, people over 60 years will represent $22 \%$ of the inhabitants of the planet.

Except in cases of total disability, life at home seems to be a desirable solution also in old age. In fact, numerous studies have found that $96 \%$ of older people choose to age independently at home. Where they have always lived. Where they are-we arethe king or the queen, be it a hut or a palace. The disadvantages occur when the 'palace hut' is cold and you cannot pay for the heating; when making food for yourself is a nuisance, and there is malnutrition; when you do not understand the washing machine and the iron is a dangerous weapon; when your legs do not respond with the required agility, and going to the shops or to the doctor is an odyssey; when you cannot make your bed, or wash yourself, or clean the dust. When the 'palace shack' becomes a cage. However, the head remains lucid and one wants to be in the same place as always, or very close to it, in the same neighborhood. Close to the familiar faces. You want to decide whether to get up or go to bed; whether to drink a chamomile or a mint, whether to turn on the TV or the radio. Or if he looks out the window. Or if he doesn't look.

The advantages of continuing life to the end in one's own home are not trivial: people develop autonomy in their environment; they avoid the feeling of being uprooted; they distance themselves from the psychological disorders linked to admission to a residential center; they show solidarity by linking up with other people in the same situation; they socialize through intergenerational coexistence; they integrate the caregivers, and even, together with their home, they become a social and economic resource in the face of other people's shortcomings. But, the problem of old age is apparently solved by public administrations, charitable foundations, or also by private investors building 'homes for the elderly'. The term sweetens the stigmatized word 'asylum', synonymous with poverty and abandonment.

Are not the residences, perhaps, a good option? Do not they provide better living conditions than housing? Do not they solve the common problem of families not having resources or means to care for their elderly? Yes, they do. Just as it solved the problem of Irma's family, one of the protagonists of the Helsinki Trilogy, a series written by Minna Lindgren: “[Irma's children and grandchildren] had sold their apartment in the Toolo district and put her in an apartment in the residence without consulting her [...] in a nursing home she was safe, and with everything they had to do at work, they didn't need to worry about whether Irma had remembered to get up and take her medicine". Certainly, a move to a residence is sometimes inevitable, and even desirable. It seems to be an economic solution for the State's coffers, and therefore, for 
the citizens, who finance them via taxes, or in the case of private ones, via direct payment. However, the coronavirus has revealed the deficiencies of the system, of the inhumanity of concentrating people in residences, forgetting, or omitting, other alternatives, as much or more efficient and economic, that incorporate mechanisms of sustainability and stimulation of the urban activity. They do require a certain creativity in management and administration. Less bureaucracy and more responsibility. Less paperwork and offices, and more being in the day-to-day.

Of course, they also demand commitment. That the administration at any of its levels intervenes in situations of need, arranging buildings and homes, or establishing agreements with the private sector, improving the comfort of the homes, providing them with an elevator, in exchange for taking over the property, for example, when the owners die. That adequate home care be organized, with collective dining rooms by neighborhoods, or by blocks, for the elderly who live alone; with common areas for laundry, and ironing... A way to reactivate the first floors, the closed premises. Everything seems to indicate that when this coronavirus nightmare is over, life will never be the same again. It is offering us the opportunity to reinvent ourselves, exploring possibilities that until now we did not contemplate, thinking that we were living in the best of all possible worlds. Now we are all old and, in a way, we are alone. The city we have built is not for old people, just as the country of Sheriff Ed Tom Bell, from Cormac Mc Carthy's novel, was not a country for old people either. 